\title{
ОСОБЕННОСТИ ВЕНЧУРНОГО ФИНАНСИРОВАНИЯ РЫНКА СВОБОДНОГО КАПИТАЛА
}

\author{
(c) 2020 Комаров Александр Глебович \\ кандидат экономических наук \\ Санкт-Петербургский государственный экономический университет, Россия, Санкт-Петербург \\ E-mail: alex.komarov64@mail.ru
}

(c) 2020 Койчу Александр Дмитриевич

бакалавр кафедры экономики и управления предприятиями и производственными комплексами Санкт-Петербургский государственный экономический университет, Россия, Санкт-Петербург

E-mail: sashako-07@mail.ru

В статье исследовано влияние краудфандинговых платформ на привлечение инвестиций. Описаны механизмы краудинвестинга в мире, его роль и преимущества для мировой экономики. Сделаны выводы о необходимости развития и поддержки отечественных краудфандинговых платформ.

Ключевые слова: венчурный капитал, краудфандинг, краудинвестинг, инновационный продукт.

Термин «венчурный капитал» появился в 50-х годах и трактовался как «рискованный капитал», его родиной принято считать США.

Как правило, все вложения, которые осуществлялись в новые проекты, имели очень высокую степень риска. В период информационного прорыва и стремительного развития технологий все больше вкладчиков стремились инвестировать свои средства в бизнес, который в короткие сроки мог бы обогатить их. Для компаний же такое инвестирование являлось альтернативой традиционным методам финансирования, так как часто в случае отсутствия собственных средств найти заинтересованного в вашей идее человека легче, чем пройти сложные процедуры в кредитных организациях. Одним из первых успешных примеров венчурного финансирования в 60-х годах прошлого века стала Кремниевая Долина, где инвесторы помогали небольшим компаниям на старте. Именно тогда стало понятно, что венчурный капитал является одним из лучших способов поддержки мелких технологических компаний. В 1978 году были зафиксированы рекордные для отрасли показатели, сумма инвестиций достигла отметки в 750 миллионов долларов США*. То же самое случилось во время бума интернет-компаний в 90-х годах, но в тот период множество венчурных фондов начали сдавать позиции и терять огромное количество денег, некоторые из них разорились. Причиной этого стал спад в телекоммуникационной отрас- ли, а также неудача многих дорогостоящих проектов, которые сворачивались без полноценного запуска. Ситуацию спасли успешные кампании по поглощению и инвестициям в инновационные организации той же телекоммуникационной отрасли. Microsoft приобрел Skype, News Corporation стал обладать сайтом MySpace. B настоящее время, венчурный капитал ассоциируют с инновациями именно из-за тех событий. Венчурное финансирование уверенно вписалось в отечественную экономическую модель, без которого её трудно представить.

На рис. 1 представлен общий объём венчурных инвестиций в мире ${ }^{* *}$. За последние 10 лет наблюдается постепенный рост, который достиг своего пика в 2018. В 2019 году произошел небольшой спад, который может быть связан с высокой активностью годом ранее.

Со временем венчурное финансирование приобрело многостороннюю форму, начали появляться венчурные фонды, управлявшие рискованными инвестициями. Они формировались из частных инвесторов, пенсионных фондов, страховых компаний и прочих организаций, которые стремились получить прибыль. Процент удачных сделок варьировался от 20 до 30 процентов, остальные проваливались и не приносили результата, но и этого небольшого процента хватало, чтобы окупить все затраты и получить выгоду.

Затем появлялись фирмы, которые помога-

\footnotetext{
* https://ru.wikipedia.org/wiki/Венчурный_капитал

** https://www.statista.com/topics/4724/venture-capital-worldwide/
} 


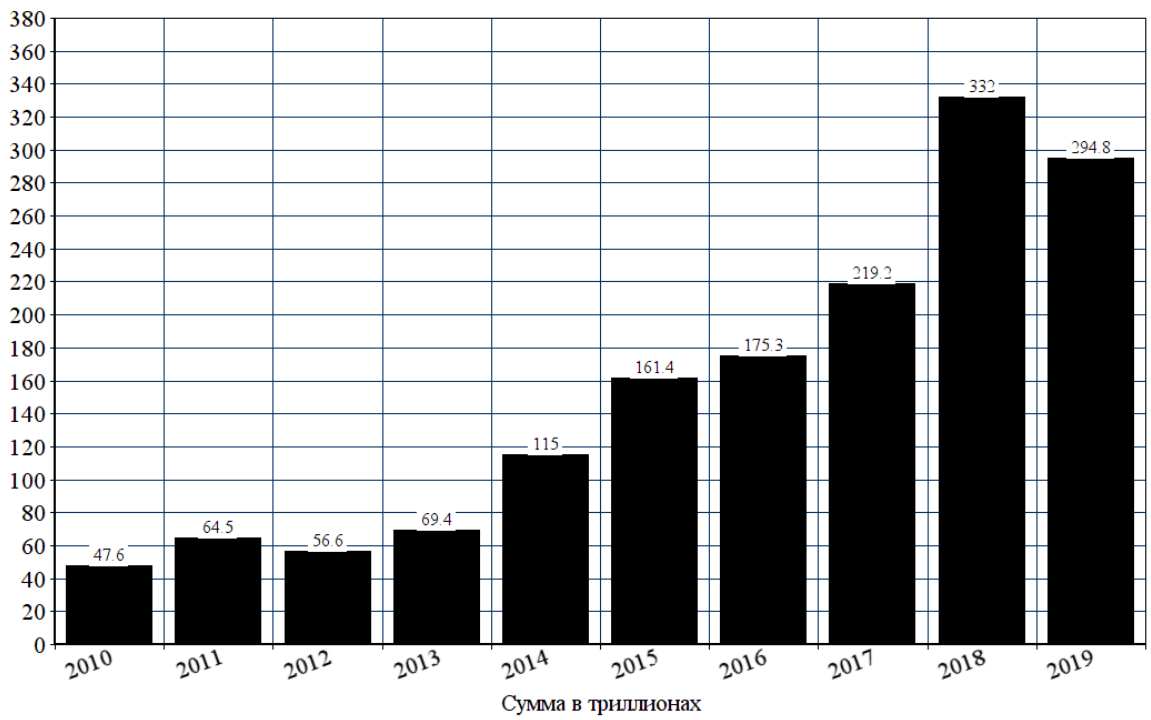

Puc. 1. Объем венчурных инвестиций

ли управлять фондами, в случае если его владельцы не справлялись и балансировали на грани бедствия. В такой сложной структуре, мелкие фирмы старались найти что-то более простое, быстрое и понятное.

Именно поэтому стали пользоваться популярностью «бизнес-ангелы». По определению Debitoor's accounting dictionary бизнес-ангел независимый инвестор, который предоставляет капитал для развития бизнеса*. И несмотря не то, что появились они еще в 90-х годах, основной рост и распространение пришлись на 2000-е года. Предприниматель, не нашедший поддержку у венчурных фондов, мог рассчитывать на поддержку в лице бизнес-ангела. Объёмы их инвестиций рознятся, но по подсчетам центра исследований венчурного финансирования, Center for Venture Research, в 2013 году в США существовало около 300 тысяч инвесторов с общим объёмом инвестиций 25 миллиардов долларов США**.

До определённого момента молодые компании пользовались указанными выше источниками финансирования. Однако прогресс не стоит на месте, и с течением времени стали появляться платформы, на которых люди самостоятельно собирали деньги на различные нужды. Появилось такое понятие как краудфандинг, которое в переводе означает народное финансирование, от англ crowd funding, crowd - «толпа», funding «финансирование». Люди собирают деньги на то, что им нужно: начиная от одежды, заканчивая серьезными старт-ап проектами.

Существует 3 модели краудфандинга:

1. Пожертвования

2. Вознаграждение

3. Акционирование

В первом случае происходит сбор средств на достижение определенных целей, когда в ответ не предусмотрены никакие награды. Во втором случае инвестор может рассчитывать на вознаграждение в любом виде: услуга, конечный продукт или что-то иное. В последнем случае инвестор имеет право на получение доли от доходов предприятия и другие преимущества.

В рамках исследования нам интересен акционированный краудфандинг, а именно «краудинвестинг». Сам по себе краудинвестинг представляет собой инструмент, который завоевал доверие в США и Европе еще в начале 2010-х годов. С развитием интернета и появлением все большего количества людей, стремящихся создать уникальный и инновационный продукт, данное решение отлично вписывается в сегодняшние реалии. Во всем мире успешно функционируют платформы, где инвесторы ищут

\footnotetext{
* Business angel - What is a business angel? https://debitoor.com/dictionary/business-angel

** https://paulcollege.unh.edu/resources/all?combine=\&resource_type=All\&field_resource_category_tid=107\&field_ resource_topic_tid $=105$
} 
старт-ап проекты, большую долю из которых составляют инновации. В США это во многом стало возможно после подписания президентом страны «Закона о стартапах», который позволил частным инвесторам вкладывать деньги в частные компании.

В отличии от краудфандинга, краудинвестинг подразумевает получение не только доли вкладчика в предприятии, которое он поддерживает, а также риска потери вкладываемых средств. Выделяют три способа получения вознаграждения от предприятия:

- Получение доли предприятия

- Получение дивидендов

- Акции предприятия

Такое инвестирование очень схоже с традиционным, но имеет одно важное отличие - оно реализуется через интернет-платформы.

В США за 2020 год стоимость сделок в сегменте краудинвестинг составляет 929,0 млн. долларов США. Ожидается, что в стоимости сделок (CAGR 2020-2023) ежегодный прирост составит 8,1\%, что к 2023 году приведет к сумме в 1174,0 млн. долларов США. В Европе дела обстоят лучше: стоимость сделок порядка 2305,6 млн. долларов США в 2020 году. Ожидаемый темп роста - 11,8\%, который к 2023 году приведет к общей сумме равной 3225,1 млн. долл. США*.

Такие объемы инвестиций стали реальны благодаря постоянному росту количества краудфандинговых платформ, а также развитию уже имеющихся.

Одна из первых платформ, лидер рынка Kickstarter, имеет специализацию на электронные гаджеты, гаджеты для дома и т.п. Одним из самых успешных и прибыльных проектов площадки стали «умные» часы Peblle. Данная платформа послужила толчком для создания альтернативных платформ по всему миру, а также подарила надежду предпринимателям, которые не смогли найти поддержку у венчурных фондов и бизнес-ангелов, на успешное воплощение их инновационных идей. Нельзя не отметить, что инновации для краудинвестинга не являлись приоритетным направлением, но с каждым годом ситуация меняется т процент инновационных проектов увеличивается.

Для России краудинвестинг понятие новое и неописанное, часто инвесторы относятся к нему скептически. И без ответа остается вопрос: по какой причине в нашей стране не удается выве- сти краудфандинг на мировой уровень?

Во-первых, россияне не до конца разобрались и поняли механизм его работы. Так как у нас это появилось совсем недавно, в отличии от западных соседей, сейчас краудинвестинг воспринимается как финансовая пирамида или сетевой маркетинг. Все устали от вечных предложений в социальных сетях о возможности вложений с получением высокой прибыли, поэтому люди обходят такие сообщения стороной.

Неосведомленность - одна из главных причин неудач российского рынка краудфандинга. У нас нет на слуху проектов, которые были реализованы в нашей стране с использованием данных платформ. Но это не значит, что они не работают. Иногда социальные сети и СМИ взрываются от новостей об успешном проекте, который был реализован в мире. 16-летний подросток собрал деньги на Kickstar на реализацию своей, казалось бы, элементарной идеи: устанавливать в ТЦ бокс со средствами первой помощи. И таких идей множество, они работают и выстреливают. Все это происходит не только на Kickstarter, есть десятки подобных платформ: IndieGoGo, Crowdfunder.com.

B качестве второй причины можно выделить техническую неконкурентоспособность отечественных платформ. Все крупные игроки используют уже имеющиеся западные ресурсы для создания заявок на получение инвестиций. Из-за этого доля отечественных инновационных проектов теряются в массе остальных, что делает проблематичным привлечение заинтересованных лиц. Некоторые крупные компании, такие как АО «Российская венчурная компания» (AO «РВК») - государственный фонд фондов и институт развития венчурного рынка Российской Федерации, стараются привлечь и инвесторов, и мелкие фирмы к взаимодействию друг с другом посредством отечественных платформ. Целью их программ является поддержка инновационной среды в регионах, так как основной массив сделок происходит в Москве и Санкт-Петербурге. Для этого создана платформа Generation-S - самый масштабный стартап-акселератор России и Восточной Европы, проводится РВК с 2013 года. В рамках акселерационных мероприятий РВК осуществляется поддержка их участников - проектных команд и компаний: менторство, обучение, экспертная поддержка, консультирование по вопросам по-

*https://www.statista.com/outlook/377/109/crowdinvesting/united-states 
лучения финансовой поддержки, подбор потенциальных стратегических инвесторов. По оценкам экспертов в 2018 году в российские стартапы было вложено более 26,7 миллиарда рублей, что на 10,4 миллиарда больше, чем в 2017 году. На рис. 2 представлены данные об объемах венчурных инвестиций в стартапы в России с 2017 на первое полугодие 2019 года (в миллионах долларов США)*.

Юридическая сторона краудинвестинга в России тоже вызывает вопросы у потенциальных участников. Только в прошлом году, 02.08.2019» был подписан закон «О привлечении инвестиций с использованием инвестиционных платформ и о внесении изменений в отдельные законодательные акты Российской Федерации». Однако закрепление инвестиционных платформ на законодательном уровне требовалось уже давно. Известно множество случаев, когда мошенники привлекали деньги, после чего проект закрывался, а все деньги присваивались недобросовестным создателям. Теперь термины «инвестиционная платформа» и «механизм инвестирования» закреплены в принятом федеральном законе (рис.3).

Подводя итог вышесказанного, стоит отметить, что краудфандинг все быстрее и масштабнее развивается в условиях цифровой экономики. С каждым годом доля инновационных проектов возрастает и позволяет появляется новым продуктам. Краудинвестинг, как финансовый инструмент позволяет аккумулировать финансовые ресурсы с мирового рынка свободного капитала, диверсифицировать инвестиционную активность, делая экономику более гибкой.

На отечественном рынке предпринимаются активные попытки к созданию благоприятных и безопасных условий для совершения сделок, что должно привести к увеличению доли венчурного капитала в общем объеме российского инвестиционного ресурса.

\footnotetext{
* обзор венчурной индустрии России за 2018 год и первое полугодие 2019 года https://www.rvc.ru/upload/ iblock/003/MoneyTree_2019_rus.pdf
}

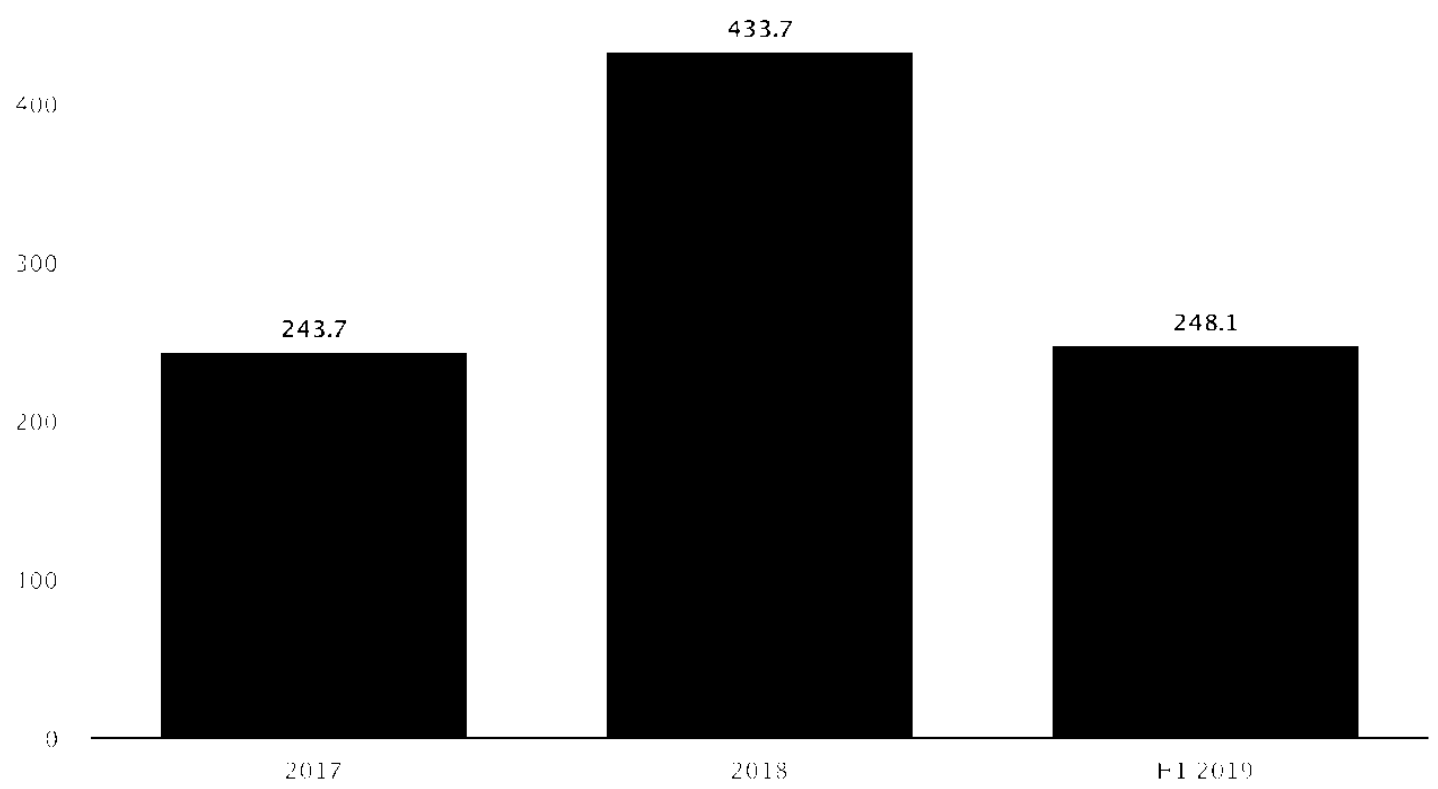

Рис 2. Объем венчурных инвестиций в стартапы России 


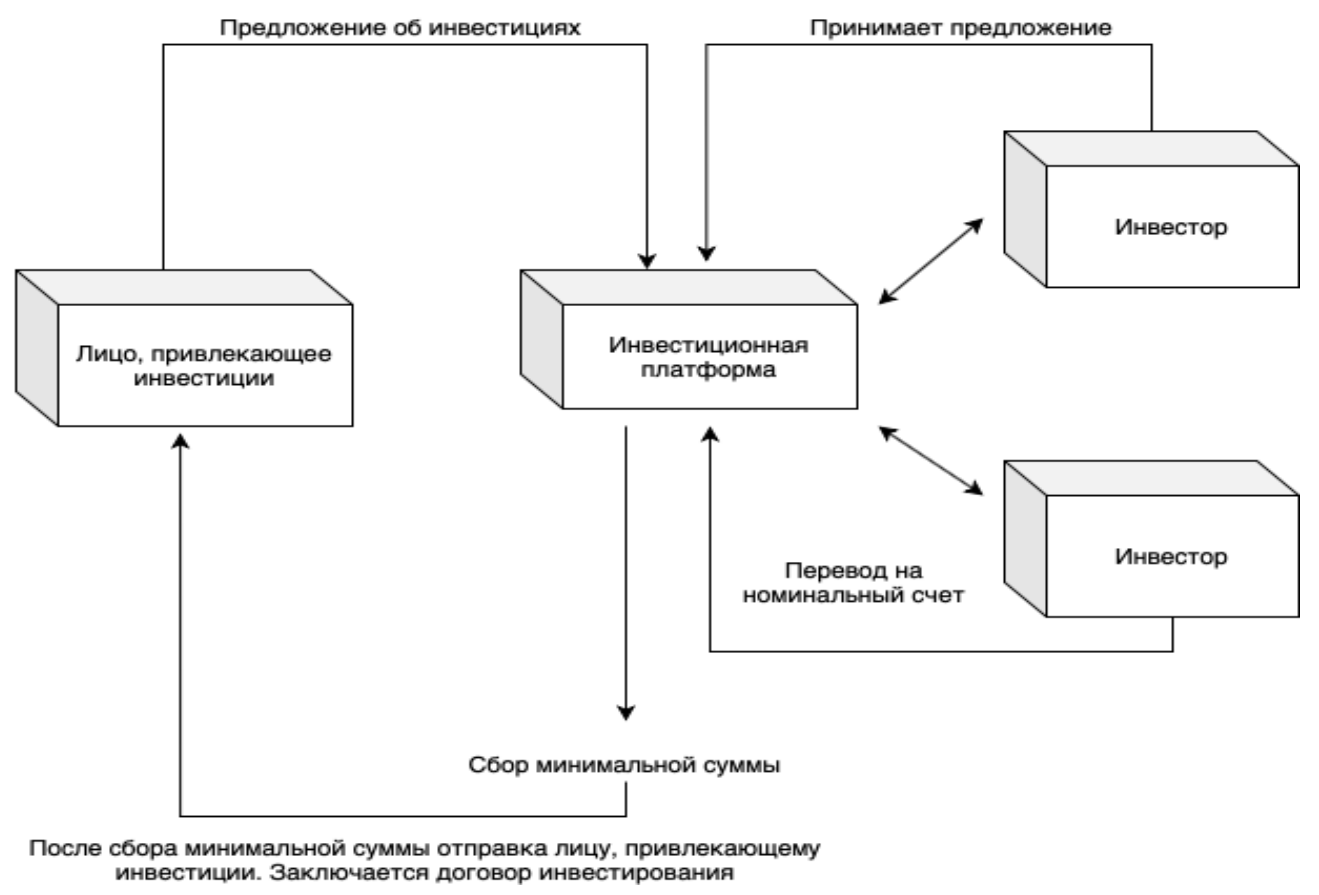

Puc. 3 Механизм инвестирования через инвестиционные платформы

Шестакова М. Закон о краудфандинге. С 2020 г. инвесторов и лиц, привлекающих инвестиции, ждут ограничения https://www.eg-online.ru/article/404885/

\section{Библиографический список}

1. Груздева Е.В. Венчурное финансирование инновационной деятельности. Учебно-метод.пос.-М.: Экономический факультет МГУ. 2018 г.

2. Шеина Е.Г., Астанакулов О. Т. - Краудинвестинг как элемент финансово-инвестиционного механизма формирования экономики опережающего развития // Налоги и налогообложение.- 2019.- № 5. - С. 20-34. DOI:

3. Мотовилов О.В. Феномен краудфандинга: исследование особенностей // Вестник Санкт-Петербургского университета. Экономика. 2018. Т. 34. Вып. 2. С. 298-316

4. Комаров А.Г. Государственное регулирование развития высокотехнологичного промышленного комплекса в условиях нестабильной экономической среды. // изд-во СПбГУЭФ 2009 с. 45-53

5. Стратегия развития рынка венчурных и прямых инвестиций до 2030 года. https://www.rvc.ru/investments/ strategy/

6. Venture capital worldwide - Statistics \& Facts https://www.statista.com/topics/4724/venture-capital-worldwide/

7. Crowdfunding scientific research: Descriptive insights and correlates of funding success https://journals.plos.org/ plosone/article?id=10.1371/journal.pone.0208384

8. Market mechanisms and funding dynamics in equity crowdfunding https://www.sciencedirect.com/science/ article/pii/S0929119916302450

9. Crowdfunding: what you need to know https://www.sciencedirect.com/science/article/pii/ S0929119916302450?via\%3Dihub

10. KPMG Private Enterprise's Global Network for Innovative Startups launched the Q2'19 edition of the Venture Pulse Report. https://home.kpmg/xx/en/home/campaigns/2019/07/venture-pulse-q2.html

11. Venture Capital Data: Opportunities and Challenges by Steven N. Kaplan and Josh Lerner https://hbswk.hbs.edu/ item/venture-capital-data-opportunities-and-challenges

12. https://www.eg-online.ru/article/404885/ 